\title{
Role of GLI2 in hypopituitarism phenotype
}

\author{
Ivo J P Arnhold, Marcela M França, Luciani R Carvalho, Berenice B Mendonca and \\ Alexander A L Jorge'
}

Divisão de Endocrinologia, Unidade de Endocrinologia do Desenvolvimento, Laboratorio de Hormonios e Genetica Molecular LIM/42, Hospital das Clinicas da FMUSP, Disciplina de Endocrinologia da Faculdade de Medicina da Universidade de Sao Paulo, Avenida Eneas de Carvalho Aguiar, 155, Prédio dos Ambulatórios, $8^{\circ}$ andar, Bloco 3, CEP 05403-900 Sao Paulo, Brazil

${ }^{1}$ Unidade de Endocrinologia Genetica, Laboratorio de Endocrinologia Celular e Molecular LIM/25, Disciplina de Endocrinologia da Faculdade de Medicina da Universidade de Sao Paulo, 01246-903 Sao Paulo, Brazil

\author{
Correspondence \\ should be addressed \\ to I J P Arnhold \\ Email \\ iarnhold@usp.br
}

\begin{abstract}
GLI2 is a zinc-finger transcription factor involved in the Sonic Hedgehog pathway. Gli2 mutant mice have hypoplastic anterior and absent posterior pituitary glands. We reviewed the literature for patients with hypopituitarism and alterations in GLI2. Twenty-five patients (16 families) had heterozygous truncating mutations, and the phenotype frequently included GH deficiency, a small anterior pituitary lobe and an ectopic/undescended posterior pituitary lobe on magnetic resonance imaging and postaxial polydactyly. The inheritance pattern was autosomal dominant with incomplete penetrance and variable expressivity. The mutation was frequently inherited from an asymptomatic parent. Eleven patients had heterozygous non-synonymous GLI2 variants that were classified as variants of unknown significance, because they were either absent from or had a frequency lower than 0.001 in the databases. In these patients, the posterior pituitary was also ectopic, but none had polydactyly. A third group of variants found in patients with hypopituitarism were considered benign because their frequency was $\geq 0.001$ in the databases. GLI2 is a large and polymorphic gene, and sequencing may identify variants whose interpretation may be difficult. Incomplete penetrance implies in the participation of other genetic and/or environmental factors. An interaction between Gli2 mutations and prenatal ethanol exposure has been demonstrated in mice dysmorphology. In conclusion, a relatively high frequency of GLI2 mutations and variants were identified in patients with congenital GH deficiency without other brain defects, and most of these patients presented with combined pituitary hormone deficiency and an ectopic posterior pituitary lobe.

Future studies may clarify the relative role and frequency of GLI2 alterations in the aetiology of hypopituitarism.
\end{abstract}

$\begin{aligned} & \text { Key Words } \\ & \text { - GLI2 } \\ & \text { - hypopituitarism } \\ & \text { - growth } \\ & \text { - mutations }\end{aligned}$

Journal of Molecular Endocrinology (2015) 54, R141-R150

\section{Introduction}

This paper reviews the evidence for GLI2 mutations as a cause of hypopituitarism.

Hypopituitarism may manifest as a deficiency of a single pituitary hormone, such as isolated growth hormone deficiency (IGHD) or combined pituitary hormone deficiency (CPHD), and it may be congenital or acquired (Kelberman et al. 2009). Congenital hypopituitarism may have a genetic, environmental or http://jme.endocrinology-journals.org DOI: 10.1530/JME-15-0009
() 2015 Society for Endocrinology Printed in Great Britain 
combined aetiology. Knowledge about genetic causes of congenital hypopituitarism has been advanced by the study of pituitary embryogenesis in animal models (natural and transgenic) and by candidate gene analysis in patients with pituitary hormone deficiencies. Although animal models have been very useful, one has to bear in mind that there may be differences when the results are extrapolated to the human (Kelberman et al. 2009).

GLI2 is a gene of the GLI-Kruppel family, which received its name because it was initially amplified in brain gliomas, and it is also known as GLI2 oncogene $\left(\mathrm{OMIM}^{\star} 165230\right)$. GLI2 is located on the long arm of chromosome 2 at position q14 (genomic coordinates GRCh37: 2:121,493,440-121,750,228). The coding region is $6.8 \mathrm{~kb}$ in length and spans 13 exons which encode for the GLI2 protein with 1586 amino acids. GLI2 is a transcription factor that contains a zinc-finger region responsible for binding to DNA (aa437-594), an aminoterminal (-NH2) region with repressor activity and a carboxy-terminal (-COOH) domain responsible for transcriptional activation (Roessler et al. 2003, 2005). Gli2 is a member of the Gli family of proteins (including Gli1 and Gli3) which are involved in the Sonic Hedgehog (Shh) signalling pathway.

SHH (Shh, OMIM*600725) induces tissue-specific cellular proliferation during embryogenesis (Villavicencio et al. 2000). After cleavage and the addition of a cholesterol molecule, Shh binds to the membrane receptor Patched releasing Smoothened, which in turn activates the Gli family of transcription factors. Gli1 and Gli2 usually act as activators, and Gli3 usually acts as a repressor; however, divergence of Gli protein function among tissues and species has been observed (Ruiz i Altaba et al. 2002).

\section{Role of the Shh/Gli2 pathway in pituitary embryogenesis}

Most of our knowledge about pituitary embryogenesis derives from murine models. In mice, the development of the pituitary results from the timely complex interaction of transcription factors and signalling molecules acting as activators or repressors, which play a crucial role in cell proliferation, cell patterning and terminal differentiation (Zhu et al. 2007). The posterior pituitary lobe derives from the neural ectoderm of the ventral diencephalon, which is part of the anterior neural placode, whereas the anterior lobe (and intermediate lobe in mice) derives from the oral ectoderm adjacent to the diencephalon (extensively reviewed by Kelberman et al. (2009)). In early stages of pituitary organogenesis, the close interaction between the invagination of the oral ectoderm to form the rudimentary Rathke's pouch and the evagination of the neuroectoderm of the ventral diencephalon to form the posterior pituitary lobe is critical for pituitary gland formation. Extrinsic signals from the ventral diencephalon and surrounding structures (WNT, BMP, FGF, Notch and Hedgehog pathways) play an important role in the early stage of pituitary embryogenesis (Zhu et al. 2007, Kelberman et al. 2009). The oral ectoderm thickens and invaginates upwards to form the Rathke's pouch, and the diencephalon evaginates downwards (Treier et al. 2001). Rathke's pouch separates and detaches from the oral ectoderm to form the pituitary gland.

During early vertebrate embryogenesis, Sonic Hedgehog (Shh, OMIM*600725) is expressed in midline tissues, such as the notochord and floor plate of the neural tube, and it is critical for distal elements of the developing limbs. Shh is expressed in the ventral diencephalon and in the adjacent oral ectoderm but not in the primordial Rathke's pouch (Treier et al. 2001). In contrast, the Shh receptor Patched is expressed in Rathke's pouch. Shh signalling is mediated by three related zinc-finger transcription factors, Gli1, Gli2, and Gli3, which are expressed in the ventral diencephalon and in the developing Rathke's pouch and lead to activation of target genes (Hui et al. 1994). Gli2 is expressed in the ventral diencephalon, where it induces $B m p 4$ and $F g f 8$ expression, and it is also expressed in the oral ectoderm, where it induces pituitary progenitors (Wang et al. 2010). In mice, inactivation of Gli2 caused severe ventral patterning defects in the hindbrain, diminished pituitary progenitor cells, caused a normally patterned but hypoplastic anterior pituitary as a result of diminished cellular proliferation and reduced expression of $B m p 4$ and $F g f 8$ with an absent posterior lobe (Lebel et al. 2007, Wang et al. 2010). The numbers of somatotropes, lactotropes and corticotropes were also diminished (Wang et al. 2010). In contrast, mice with inactivated Gli1 or Gli3 had no pituitary abnormalities (Wang et al. 2010).

By in situ hybridisation and immunostaining, Gregory et al. (2015) showed widespread expression of GLI2 within the neural epithelium, including the hypothalamus, head mesenchyme and developing Rathke's pouch, in human embryos at Carnegie stages 13 and 15. Widespread Gli2 expression has previously been described in mouse embryos at comparable developmental stages (11-12 days post coitum) (Hui et al. 1994), which demonstrates that GLI2 is expressed during human development at the critical stages when Gli2 activity is required in the mouse (Gregory et al. 2015).

Published by Bioscientifica Ltd. 
A mutant zebrafish with loss-of-function gli2 (yoo-too, yot) was shown to have anterior pituitary hypoplasia and abnormal patterning of the ventral CNS (Karlstrom et al. 2003).

\section{Human mutations}

SHH mutations are a genetic cause of holoprosencephaly (HPE), which is characterised by a failure of midline division of the forebrain. Clinical manifestations are variable, ranging from closely spaced eyes (hypotelorism) to the failure of the eye field and forebrain to separate, which is associated with cyclopia (Roessler et al. 2003). GLI2 is a mediator of SHH action and is, therefore, a candidate gene for HPE. Roessler et al. (2003, 2005) isolated the human GLI2 gene and searched for mutations in 390 patients who met clinical criteria for HPE. Very few patients had GLI2 mutations that, in addition to HPE, were noted to have polydactyly, midfacial and/or pituitary abnormalities. The authors observed an autosomal dominant inheritance with incomplete penetrance and inferred that pituitary and facial structures were more sensitive to a reduction in GLI2 activity than the ventral forebrain was. Subsequently, Rahimov et al. (2006) screened GLI2 in patients with isolated midfacial defects, and França et al. (2010) screened patients with isolated pituitary hormone deficiency without HPE. In this review, we concentrate on the GLI2 mutations in patients that have a pituitary phenotype with or without additional abnormalities.

A comprehensive review of GLI2 mutations also in subjects without hypopituitarism that included patients with HPE and/or midfacial defects or their normal relatives has been published by Bear et al. (2014).

Several different heterozygous GLI2 variants have been reported in patients with hypopituitarism, and some of these variants have been reported in databases of normal individuals. It is not clear if all of them have clinical significance. GLI2 mutations with a functional effect may be found in normal individuals because the penetrance is incomplete and its percentage is presently unknown. Incomplete penetrance also indicates that the mutation alone is probably not enough to cause the phenotype but instead must be coupled to other genetic and/or environmental factors.

In this review, we take a conservative approach and classify variants in three groups: i) highly likely to cause the phenotype: complete gene deletions, nonsense or frameshift mutations that result in protein truncation, mutations in the universal splicing sites $(-2,-1,+1$ or +2$)$ and mutations within the zinc-finger region with impaired functional test (Table 1); ii) variants of unknown significance: non-synonymous variants with normal or absence of functional tests but absent or with an allele frequency lower than 0.001 in Exome Variant Server (EVS) and Exome Aggregation Consortium (ExAC browser, http://exac.broadinstitute.org; updated 18/02/2015) and/or local control individuals (Table 2); and iii) probably benign: variants with a frequency $\geq 0.001$ (equivalent to $0.1 \%$ ) in the EVS or ExAC browser.

Table 1 displays 25 patients from 16 families where the GLI2 mutation has led to a severe alteration in the GLI2 protein, including: one family with a complete gene deletion, six with termination codons, six with frameshift mutations that resulted in stop codons, one with a mutation in the universal splicing site and two with mutations in the zinc-finger region and functional tests that show impaired transactivation.

Roessler et al. (2005) performed luciferase-based reporter assays in cultured mouse $\mathrm{C} 3 \mathrm{H}$ cells to test GLI2 transcriptional activity. The human GLI2 carboxyterminal domain had transcriptional activity, whereas the amino-terminal domain had transcriptional repressor activity, which was similar to reported findings in mice Gli2 (Sasaki et al. 1999, Roessler et al. 2005). Constructs that represent pathogenic human GLI2 mutants with intact amino-terminal and zinc-finger domains and a truncated carboxy-terminal domain showed no intrinsic Gli2 transcriptional activity. Cotransfection of these mutants, together with WT GLI2, revealed strong dominant negative activity as compared to WT alone. Intact zinc-finger as well as amino-terminal domains were important for the preservation of dominant negative activity (Roessler et al. 2005). The GLI2 p.Arg516Pro mutation reported by Flemming et al. (2013) in patient $4 \mathrm{a}$ is located in the third zinc finger of the DNA-binding domain. Electromobility shift assay demonstrated a lack of binding to a consensus GLI-binding site, and luciferase reporter assay revealed a complete loss of transactivation in mouse embryonic fibroblast (NIH-3T3) as well as murine corticotrophinoma (At-T 20) cell systems. Further experiments showed no dominant negative behaviour of this mutation, which confirmed previous studies that required integrity of the DNA-binding domain for this effect (Roessler et al. 2005, Flemming et al. 2013). The authors suggested a dose effect or even autosomal random monoallelic expression. The two-amino-acid-apart GLI2 p.Glu518Lys mutation reported by Gregory et al. (2015) had normal binding on the electromobility shift assay but

Published by Bioscientifica Ltd 


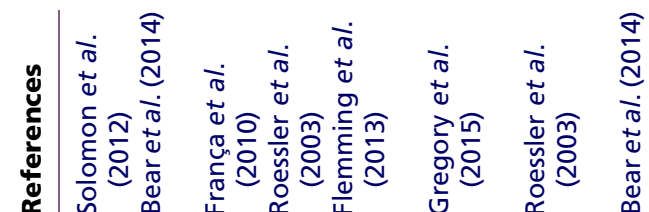

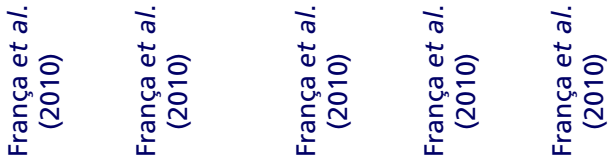
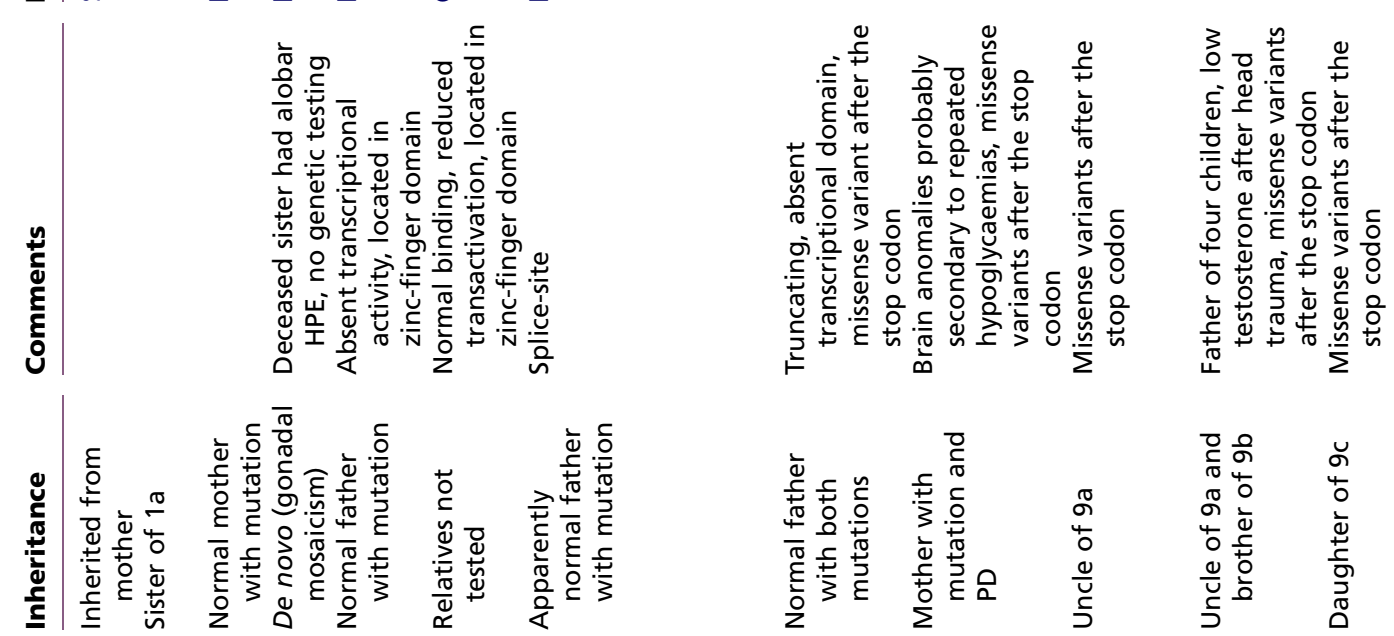

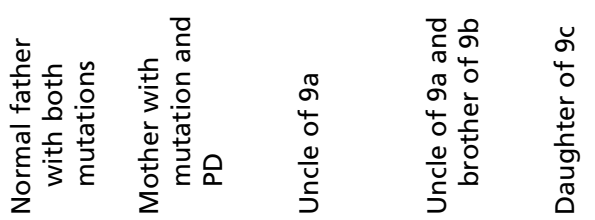
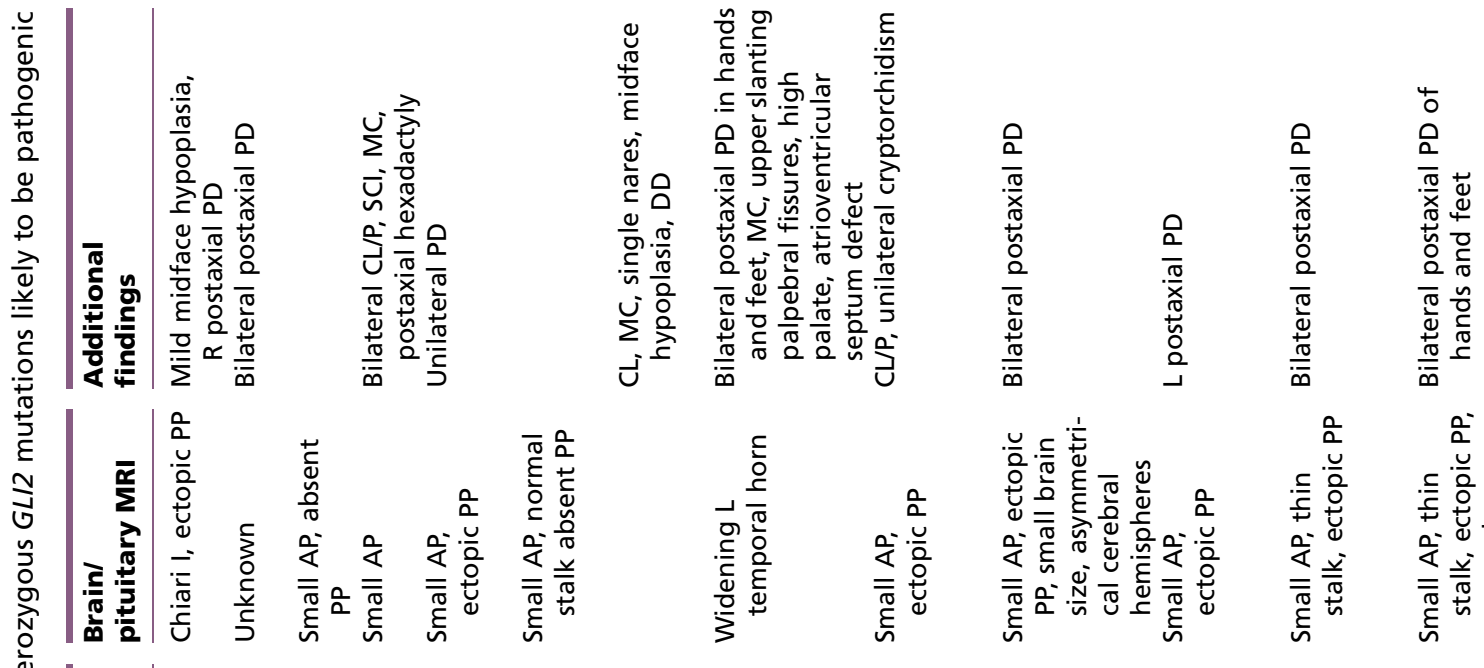

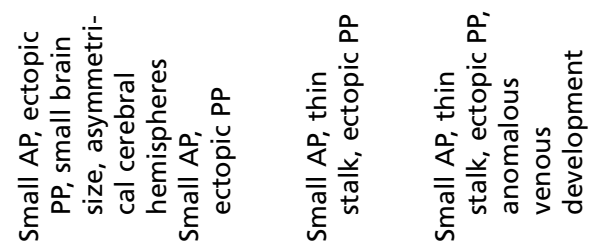

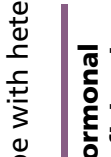

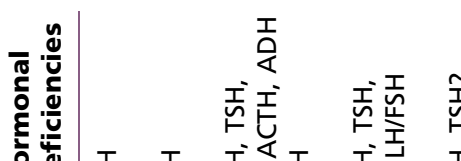

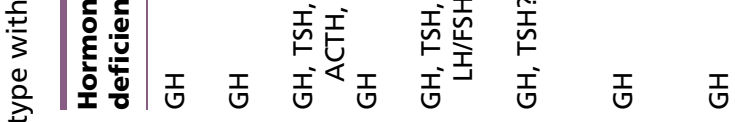

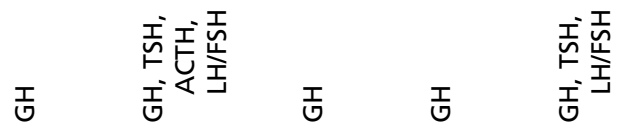
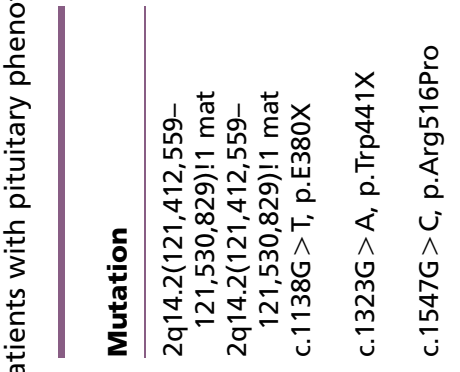

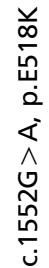

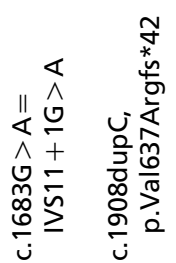

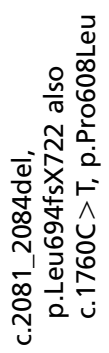
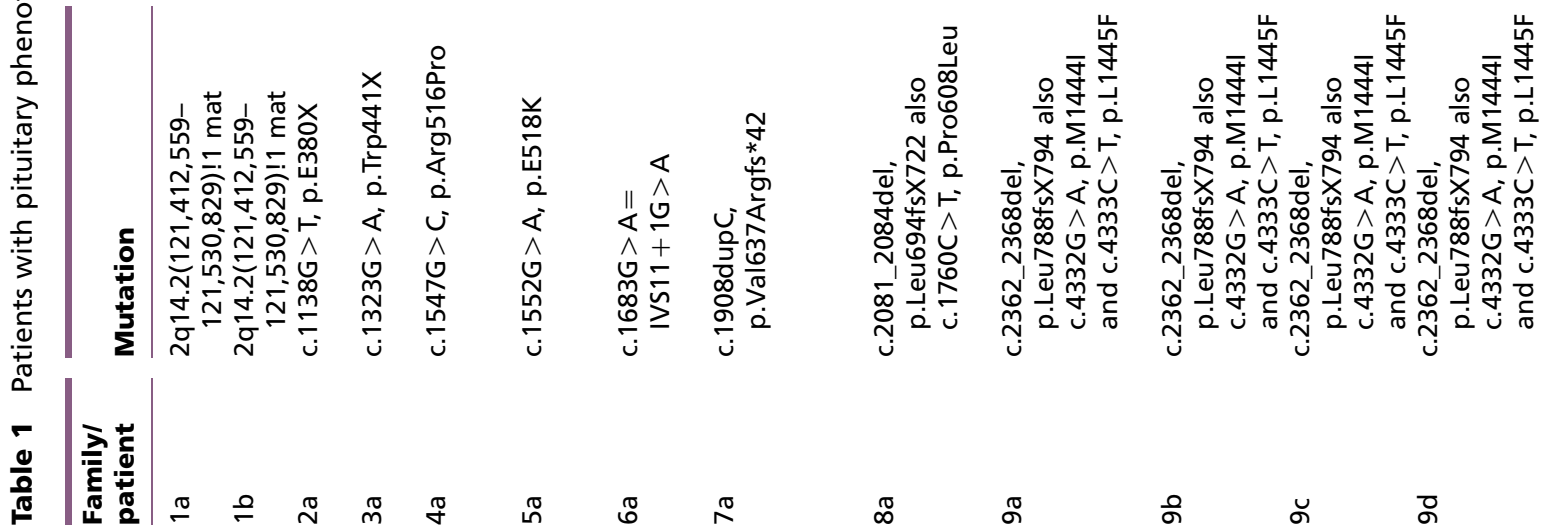

○

$$
\text { ำ }
$$

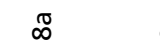

ภ็

क ㅁ 음 


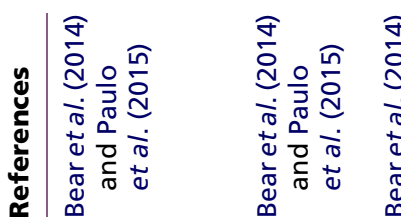

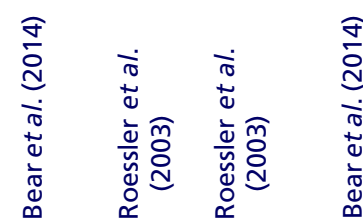

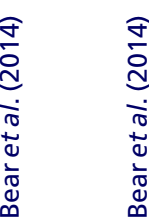
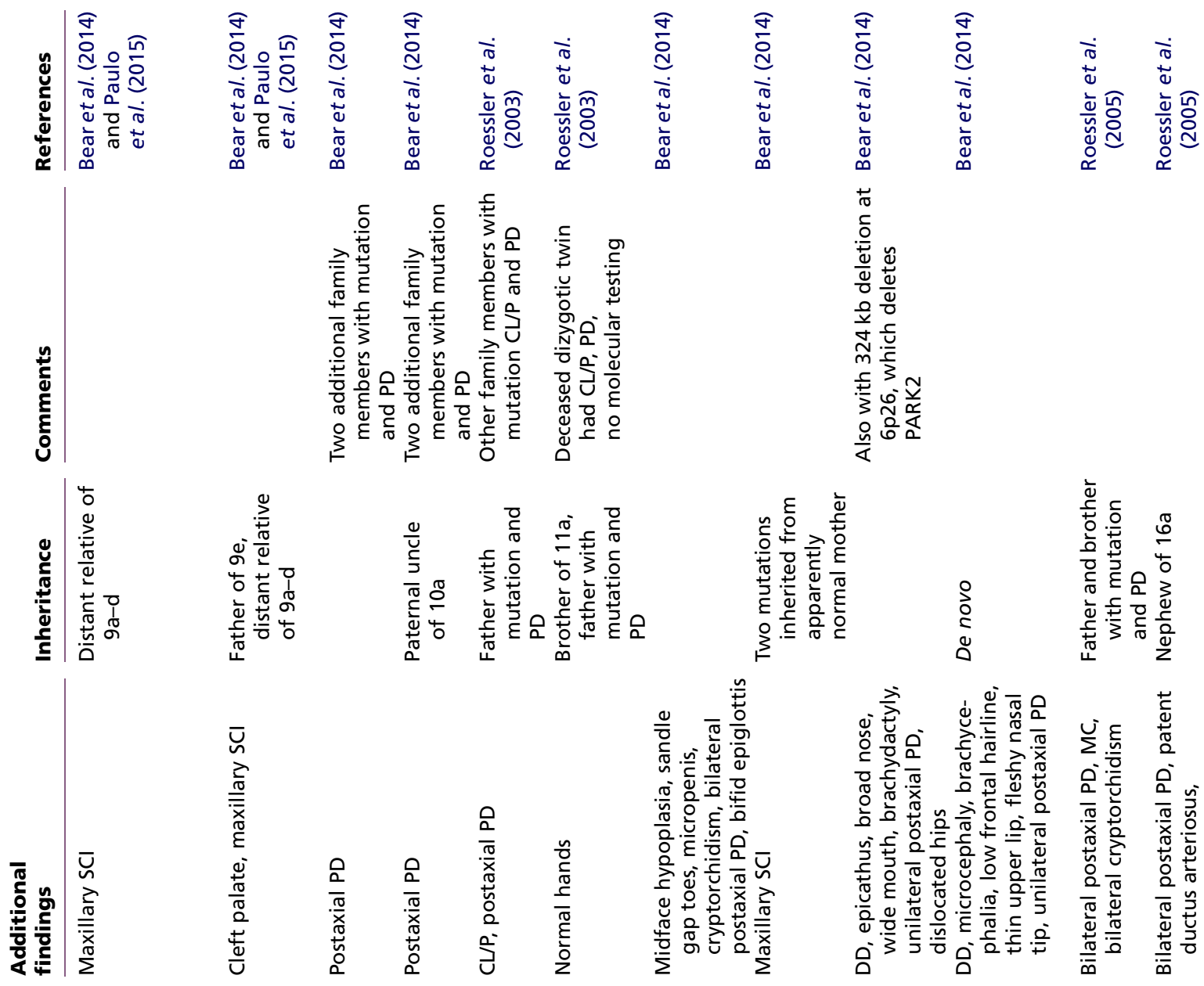

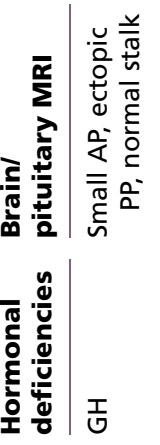

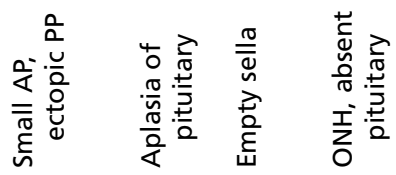

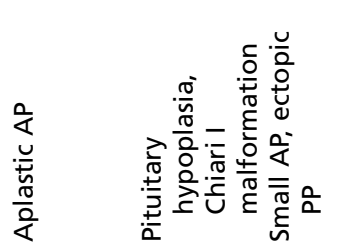
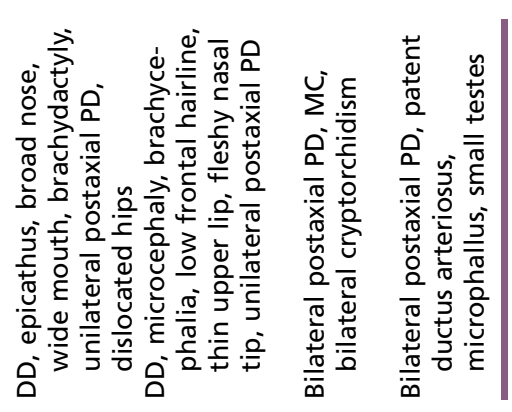

뭉

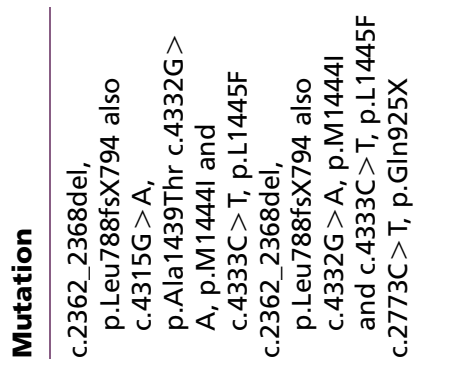

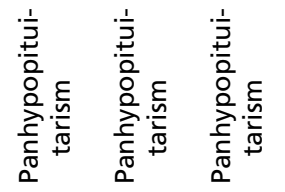
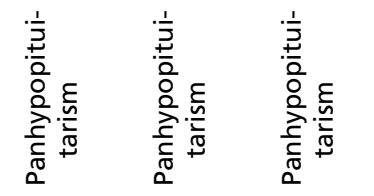

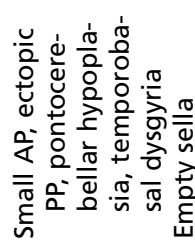
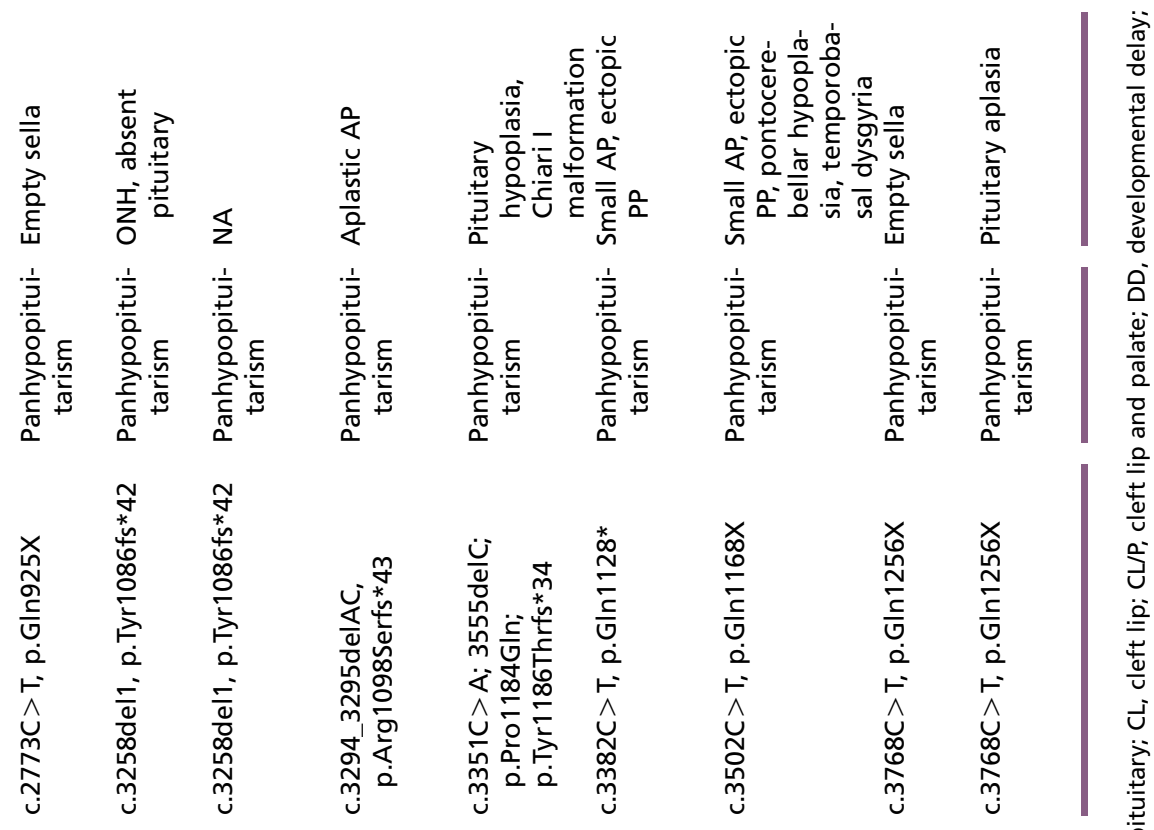

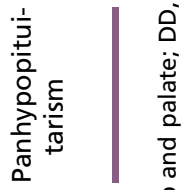




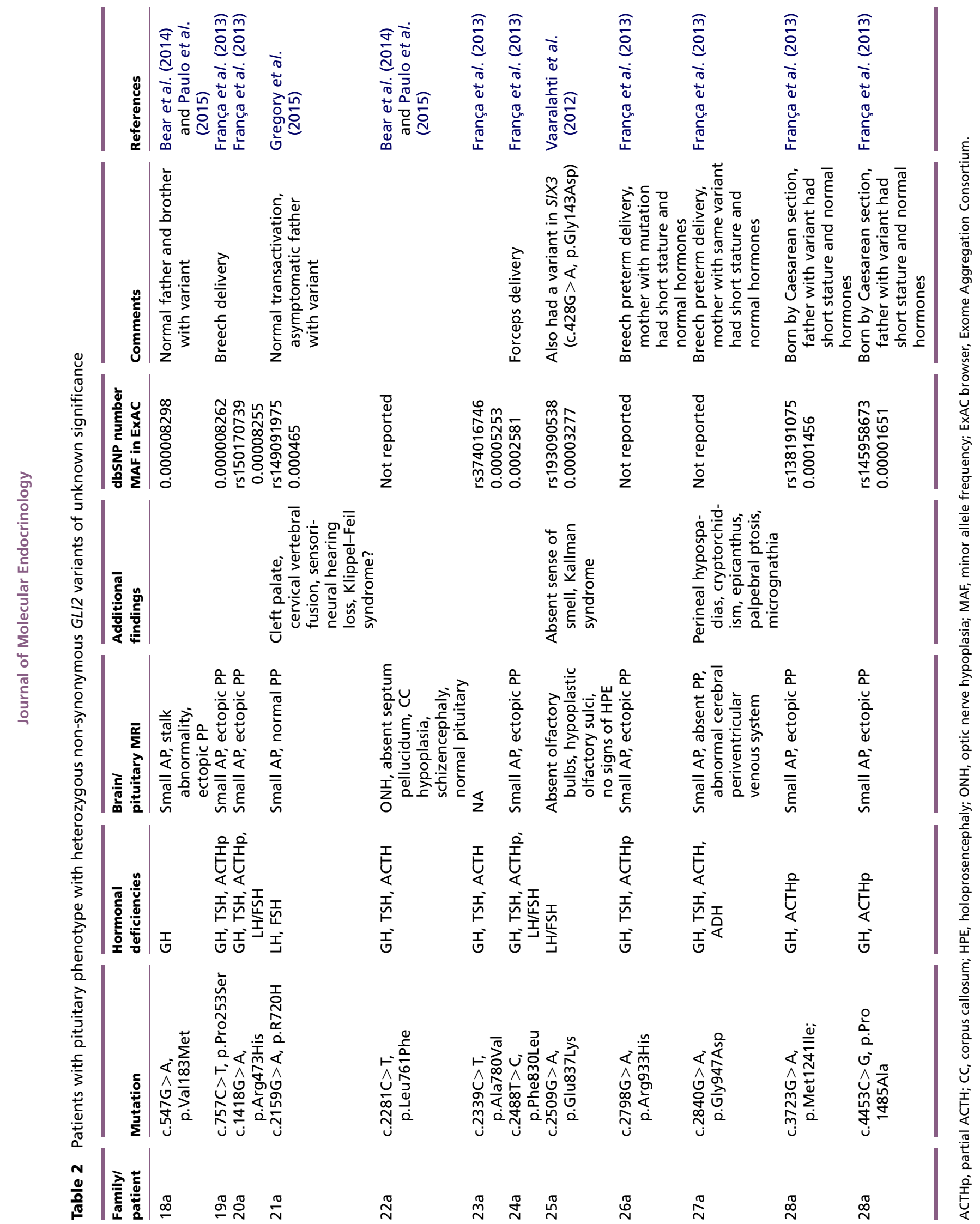


significantly reduced transactivation in a reporter assay that also uses NIH 3T3 cells.

Seventeen (68\%) of the 25 patients in Table 1 had polydactyly, whereas none of the patients in Table 2 had polydactyly, which suggests that only major GLI2 abnormalities result in polydactyly. Similar findings have been observed by Bear et al. (2014): 16/26 (62\%) of severe mutations had polydactyly in addition to pituitary abnormalities, whereas only $1 / 58(2 \%)$ with milder variants had both hand and pituitary defects. The presence of polydactyly in a patient with hypopituitarism or in one of his relatives may be an additional indication that the GLI2 gene should be studied (França et al. 2010). Interestingly, mice with targeted disruption of Gli2 have not been shown to have digit abnormalities unless Gli1 is also deleted, which emphasizes the difference between Gli protein functions in vertebral species (Roessler et al. 2005).

Molecular testing was performed in several parents of the probands with hypopituitarism in Table 1: of the 11 parents who carried the same mutation, two had hypopituitarism (one with polydactyly), three had only polydactyly and six were apparently completely normal. This indicates that even with the most severe mutations, the penetrance is incomplete. Therefore, in addition to the GLI2 mutation, another genetic and/or environmental factor is probably responsible for the pituitary phenotype.

An interaction between specific genetic and environmental risk factors has been demonstrated in mice by Kietzman et al. (2014). Heterozygous Shh and Gli2 mice exposed to prenatal ethanol had, respectively, a 3.2- and a 6.6-fold increase in their dysmorphology score as compared to WT littermates that were exposed to the same ethanol protocol. The authors also observed a close correlation between the severity of facial dysmorphology and midline forebrain abnormalities in affected animals (Kietzman et al. 2014).

The phenotypic expressivity of GLI2 mutations is variable. The largest family with GLI2 mutations reported to date had the p.Leu788fsX794 mutation (França et al. 2010, Paulo et al. 2015). In the family reported by França et al. (2010), the ten subjects who tested positive for the mutation also had polydactyly, whereas in the two distant relatives with the same mutation studied by Paulo et al. (2015) in a different city, polydactyly was not observed. Among the six patients with hypopituitarism, four had IGHD and two had CPHD, independent of age. The two patients reported by Paulo et al (2015). had a median solitary maxillary incisor, one with cleft palate, but this was not observed in the patients studied by França et al (2010). Therefore, the phenotypic variability in this family with the same mutation ranged from polydactyly only to IGHD or CPHD, with the presence or absence of cleft palate and of a median solitary maxillary incisor. None of the patients had brain abnormalities characteristic of HPE. Interestingly, all of the patients with hypopituitarism in this family had a small anterior lobe and an ectopic posterior lobe on pituitary magnetic resonance imaging (MRI).

After an extensive review of more than 400 patients, Bear et al. (2014) concluded that frank HPE resulting from pathogenic GLI2 mutations is rare. The absence of forebrain abnormalities in patients with GLI2 mutations, as opposed to those with $\mathrm{SHH}$ mutations, might be related to the maintained activity of GLI3 in the former. Shhdependent ventral patterning in the neural tube is preserved in Gli1/Gli2 double homozygous mutant mice embryos, which suggests that Gli3 partly compensates for the function of Gli2 (Sasaki et al. 1999).

An ectopic or undescended posterior pituitary lobe is a frequent finding in patients with hypopituitarism resulting from GLI2 mutations. An ectopic or undescended posterior pituitary lobe is also a frequent finding in patients with GH deficiency, especially CPHD. Its presence on MRI has been increasingly used for the diagnosis of GH deficiency in light of the limitations of GH stimulation tests. Among most patients with an ectopic or undescended posterior pituitary lobe, rare mutations in factors involved in early pituitary embryogenesis have been reported, including: HESX1 (Dattani et al. 1998, Alatzoglou \& Dattani 2009), LHX4 (Machinis et al. 2001, Alatzoglou \& Dattani 2009), SOX3 (Woods et al. 2005, Solomon et al. 2007) and OTX2 (Diaczok et al. 2008, Dateki et al. 2010). In addition, mutations in these early acting factors may present as part of a syndrome in patients that manifest abnormalities in extra-pituitary structures that share a common embryological origin with the pituitary gland, such as the eye and forebrain. However, mutations in these factors have been identified in only a minority of patients that have hypopituitarism with an ectopic posterior lobe, and GLI2 mutations might be a significant genetic cause of additional cases (França et al. 2013).

Mutations in PROP1 are the most common genetic cause of CPHD in many geographical areas, but the inheritance is autosomal recessive with complete penetrance, and in all patients, the posterior pituitary lobe has been shown to have a normal position (Wu et al. 1998, Kelberman et al. 2009). Interestingly, the posterior pituitary lobe has been consistently in a normal position in patients with mutations in transcription factors that act late, and expression is restricted to the Rathke's pouch, such as PROP1 and POU1F1 (PIT1) (Alatzoglou \& Dattani 2009).

Published by Bioscientifica Ltd. 
Two patients (2a and 27a, Tables 1 and 2) also had diabetes insipidus. ADH deficiency might be explained because GLI2 is also expressed in the ventral diencephalon, and it is important for hypothalamus, infundibulum and posterior pituitary lobe formation (Wang et al. 2010). All of the mice with Gli2 mutations had no posterior pituitary, which suggests that Gli2 is a requirement for ventral diencephalon formation (Wang et al. 2010). Interestingly, patient 2a with a nonsense mutation (p.E380X) had diabetes insipidus at the age of 18 months and reached a urinary osmolality of $613 \mathrm{mOsm} / \mathrm{kg} \mathrm{H}_{2} \mathrm{O}$ during follow-up at the age of 30 months (França et al. 2010).

In one patient, diabetes insipidus and semilobar HPE were initially attributed to a GLI2 p.Arg226His variant (Roessler et al. 2003). However, the patient was later found to also have a truncating mutation in ZIC2, and there was stronger evidence that this was the cause of HPE and ADH deficiency in that individual (Solomon et al. 2009).

Diabetes insipidus is common in typical HPE, whereas in patients with GLI2 mutations, there is frequent anterior pituitary hormone deficiency (Bear et al. 2014).

It is noteworthy that patient 27 a with the GLI2 p.Gly947Asp variant had, in addition to hypopituitarism, incomplete masculinisation of the external genitalia. Miyagawa et al. (2011) have shown that Shh is expressed in the urethral plate epithelium of mice during embryogenesis and that its signal is mediated through Gli2 in the mesenchyme. Gli2 mutants had hypoplasia of the genital tubercle and a cleft at the proximal ventral midline without androgen deficiency. This murine phenotype resembles that patient's hypospadias. However, the boys with other GLI2 sequence variants or nonsense mutations had normal external genitalia, which indicates that additional, as-yet-unidentified factors modulate the phenotype.

The greater prevalence of GH deficiency among hypopituitary patients that harbour GLI2 mutations might be explained by an ascertainment bias, because more cohorts of patients with GH deficiency have been studied. Furthermore, Gli2 knockout mice have a reduced number of somatotrophs, and these represent the largest population of pituitary hormone-secreting cells (Wang et al. 2010).

Vaaralahti et al. (2012) screened HPE genes in 19 patients with Kallman syndrome who were negative for known candidate gene mutations. One patient (25a, Table 2) had the GLI2 p.Glu837Lys variant (Table 2) in addition to a SIX3 p.Gly143Asp. He had gonadotrophin deficiency but no evidence of other characteristics of patients with GLI2 mutations, such as GH hormone deficiency, ectopic posterior pituitary lobe or polydactyly. Although the pathogenicity of these variants was not proven, the authors suggested an overlap between HPE and Kallman syndrome genes.

Larger deletions of chromosome 2q, including GLI2 and several additional genes, have been described. Kevelam et al. (2012) reported a heterozygous submicroscopic $1.3 \mathrm{~kb}$ deletion of $2 \mathrm{q} 14.2$ in a patient with a cleft lip and palate and panhypopituitarism. Gustavsson et al. (2006) described a balanced translocation and a

Table 3 Heterozygous GLI2 variants identified in patients with hypopituitarism and found with a frequency of more than 0.001 in updated databases

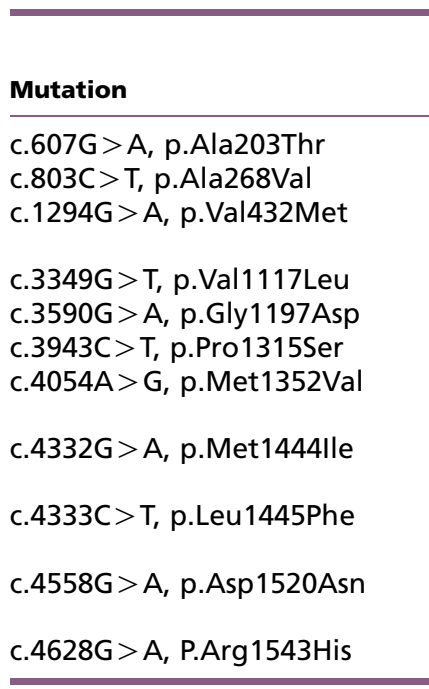

\begin{tabular}{|c|c|c|}
\hline \multirow[b]{2}{*}{ dbSNP number } & \multicolumn{2}{|c|}{ Minor allele frequency } \\
\hline & EVS & ExAC browser \\
\hline rs147044066 & 0.0013090 & 0.0007559 \\
\hline rs146992756 & 0.0022347 & 0.0007070 \\
\hline rs142296407 & 0.0042467 & 0.001509 \\
\hline rs147580961 & 0.0022347 & 0.0005250 \\
\hline rs114823319 & 0.0049115 & 0.001446 \\
\hline rs114376238 & 0.0192021 & 0.01649 \\
\hline rs149140724 & 0.0108065 & 0.009916 \\
\hline rs146467786 & 0.000769 & 0.008259 \\
\hline rs146207623 & 0.000769 & 0.008258 \\
\hline rs114814747 & 0.0110385 & 0.01005 \\
\hline rs138987487 & 0.0004615 & 0.0005028 \\
\hline
\end{tabular}

\section{References}

França et al. (2013)

França et al. (2013)

França et al. (2013), Bear et al. (2014) and Paulo et al. (2015)

França et al. (2013)

França et al. (2013)

França et al. (2013)

Flemming et al. (2013), França et al. (2013) and Paulo et al. (2015)

Flemming et al. (2013), França et al. (2013) and Paulo et al. (2015)

Flemming et al. (2013), França et al. (2013) and Paulo et al. (2015)

Flemming et al. (2013), França et al. (2013) and Paulo et al. (2015)

Flemming et al. (2013)

EVS, Exome Variant Server; ExAC browser, Exome Aggregation Consortium.

http://jme.endocrinology-journals.org DOI: 10.1530/JME-15-0009
(C) 2015 Society for Endocrinology Printed in Great Britain
Published by Bioscientifica Ltd 
submicroscopic deletion of 2q14.2-2q22.1 that included 42 known genes in addition to GLI2 with a complex phenotype that included, among others, polydactyly, GH deficiency, hypospadias and undescended testes.

Table 3 shows heterozygous non-synonymous GLI2 variants that were reported in isolation or in combination in patients with hypopituitarism and were probably benign, because their frequency in updated databases of normal individuals was $\geq 0.001$. However, the 0.001 threshold is arbitrary, because the true prevalence of hypopituitarism resulting from GLI2 mutations is unknown, as is the penetrance of GLI2 mutations, which may also vary according to each specific mutation. Therefore, it is premature to conclude that these variants have no effect on the phenotype. Functional studies are useful, but they also have limitations because of their artificial nature. It is possible that after a few years of whole exome and genome sequencing of large cohorts of patients with hypopituitarism, the relative contribution of variants in different genes will be better understood. There is also a selection bias of the types of patients that are screened with the candidate gene approach. Because the GLI2 gene will be included in the analysis in different conditions that are submitted to whole exome/genome sequencing in future studies, the range of phenotypes associated with each GLI2 mutation will likely be further expanded.

The exact frequency of GLI2 alterations in patients with hypopituitarism is still difficult to determine because of the ascertainment bias in and the phenotypic heterogeneity of studied patient cohorts as well as different GLI2 screening methods and a lack of proof of pathogenicity for many GLI2 variants. Among 284 patients with hypopituitarism from three cohorts in whom the complete coding region of GLI2 was sequenced, 15 patients (5\%) had either loss-of-function or non-synonymous GLI2 variants found in updated databases with a frequency lower than 0.001 (França et al. 2013, Gregory et al. 2015, Paulo et al. 2015).

The aetiology of congenital GH deficiency in most cases is still unknown. The presence of familial cases suggests a genetic origin instead of a traumatic/ischaemic origin secondary to perinatal insults (Phillips \& Cogan 1994, Triulzi et al. 1994). However, in most cases of GH deficiency, the family history is apparently not positive for similar cases. A disease model of partial penetrance, as with GLI2 mutations, indicates that the possibility of hypopituitarism and/or polydactyly should be investigated even in distant relatives. One of the index patients had two uncles with IGHD who were unaware of their condition (França et al. 2010).
GLI2 is a large and polymorphic gene, and sequencing may identify variants of unknown significance whose interpretation may be difficult. GLI2 variants might interact with environmental and other genetic factors to modulate the phenotype. Functional analyses of GLI2 variants are important to add evidence to their pathogenicity.

In conclusion, a relatively high frequency of GLI2 mutations and variants was identified in patients with congenital GH deficiency without other brain defects, and most of these patients presented with CPHD and an ectopic posterior pituitary lobe. Future studies may clarify the relative role and frequency of GLI2 alterations in the aetiology of hypopituitarism.

\section{Declaration of interest}

The authors declare that there is no conflict of interest that could be perceived as prejudicing the impartiality of this review.

\section{Funding}

This review was supported by the Sao Paulo Research Foundation (FAPESP) (grant numbers 05/04726-0 and 07/56490-5 to M M F and grant number 2013/03236-5 to A A L J) and by the National Council for Scientific and Technological Development (CNPq) (grant number 307922/2013-8 to I J P A, grant number 301339/2008-9 to B B M and grant number 304678/2012-0 to $A A L J)$.

\section{References}

Alatzoglou KS \& Dattani MT 2009 Genetic forms of hypopituitarism and their manifestation in the neonatal period. Early Human Development 85 705-712. (doi:10.1016/j.earlhumdev.2009.08.057)

Bear KA, Solomon BD, Antonini S, Arnhold IJ, França MM, Gerkes EH, Grange DK, Hadley DW, Jaaskelainen J, Paulo SS et al. 2014 Pathogenic mutations in GLI2 cause a specific phenotype that is distinct from holoprosencephaly. Journal of Medical Genetics 51 413-418. (doi:10.1136/jmedgenet-2013-102249)

Dateki S, Kosaka K, Hasegawa K, Tanaka H, Azuma N, Yokoya S, Muroya K, Adachi M, Tajima T, Motomura K et al. 2010 Heterozygous orthodenticle homeobox 2 mutations are associated with variable pituitary phenotype. Journal of Clinical Endocrinology and Metabolism 95 756-764. (doi:10.1210/jc.2009-1334)

Dattani MT, Martinez-Barbera JP, Thomas PQ, Brickman JM, Gupta R, Martensson IL, Toresson H, Fox M, Wales JK, Hindmarsh PC et al. 1998 Mutations in the homeobox gene HESX1/Hesx1 associated with septooptic dysplasia in human and mouse. Nature Genetics 19 125-133. (doi:10.1038/477)

Diaczok D, Romero C, Zunich J, Marshall I \& Radovick S 2008 A novel dominant negative mutation of OTX2 associated with combined pituitary hormone deficiency. Journal of Clinical Endocrinology and Metabolism 93 4351-4359. (doi:10.1210/jc.2008-1189)

Flemming GM, Klammt J, Ambler G, Bao Y, Blum WF, Cowell C, Donaghue K, Howard N, Kumar A, Sanchez J et al. 2013 Functional characterization of a heterozygous GLI2 missense mutation in patients with multiple pituitary hormone deficiency. Journal of Clinical Endocrinology and Metabolism 98 E567-E575. (doi:10.1210/jc.2012-3224) 
França MM, Jorge AA, Carvalho LR, Costalonga EF, Vasques GA, Leite CC, Mendonca BB \& Arnhold IJ 2010 Novel heterozygous nonsense GLI2 mutations in patients with hypopituitarism and ectopic posterior pituitary lobe without holoprosencephaly. Journal of Clinical Endocrinology and Metabolism 95 E384-E391. (doi:10.1210/jc.2010-1050)

França MM, Jorge AA, Carvalho LR, Costalonga EF, Otto AP, Correa FA, Mendonca BB \& Arnhold IJ 2013 Relatively high frequency of nonsynonymous GLI2 variants in patients with congenital hypopituitarism without holoprosencephaly. Clinical Endocrinology 78 551-557. (doi:10.1111/cen.12044)

Gregory LC, Gaston-Massuet C, Andoniadou CL, Carreno G, Webb EA, Kelberman D, McCabe MJ, Panagiotakopoulos L, Saldanha JW, Spoudeas HA et al. 2015 The role of the sonic hedgehog signalling pathway in patients with midline defects and congenital hypopituitarism. Clinical Endocrinology 82 728-738. (doi:10.1111/cen.12637)

Gustavsson P, Schoumans J, Staaf J, Jönsson G, Carlsson F, Kristoffersson U, Borg A, Nordenskjöld M \& Dahl N 2006 Hemizygosity for chromosome 2q14.2-q22.1 spanning the GLI2 and PROC genes associated with growth hormone deficiency, polydactyly, deep vein thrombosis and urogenital abnormalities. Clinical Genetics 69 441-443. (doi:10.1111/ j.1399-0004.2006.00601.x)

Hui CC, Slusarski D, Platt KA, Holmgren R \& Joyner AL 1994 Expression of three mouse homologs of the Drosophila segment polarity gene cubitus interruptus, Gli, Gli-2, and Gli-3, in ectoderm- and mesoderm-derived tissues suggests multiple roles during postimplantation development. Developmental Biology 162 402-413. (doi:10.1006/dbio.1994.1097)

Karlstrom RO, Tyurina OV, Kawakami A, Nishioka N, Talbot WS, Sasaki H \& Schier AF 2003 Genetic analysis of zebrafish gli1 and gli2 reveals divergent requirements for gli genes in vertebrate development. Development 130 1549-1564. (doi:10.1242/dev.00364)

Kelberman D, Rizzoti K, Lovell-Badge R, Robinson IC \& Dattani MT 2009 Genetic regulation of pituitary gland development in human and mouse. Endocrine Reviews 30 790-829. (doi:10.1210/er.2009-0008)

Kevelam SH, van Harssel JJ, van der Zwaag B, Smeets HJ, Paulussen AD \& Lichtenbelt KD 2012 A patient with a mild holoprosencephaly spectrum phenotype and heterotaxy and a $1.3 \mathrm{Mb}$ deletion encompassing GLI2. American Journal of Medical Genetics. Part A 158A 166-173. (doi:10.1002/ajmg.a.34350)

Kietzman HW, Everson JL, Sulik KK \& Lipinski RJ 2014 The teratogenic effects of prenatal ethanol exposure are exacerbated by Sonic Hedgehog or GLI2 haploinsufficiency in the mouse. PLoS ONE 9 e89448. (doi:10.1371/journal.pone.0089448)

Lebel M, Mo R, Shimamura K \& Hui CC 2007 Gli2 and Gli3 play distinct roles in the dorsoventral patterning of the mouse hindbrain. Developmental Biology 302 345-355. (doi:10.1016/j.ydbio.2006.08.005)

Machinis K, Pantel J, Netchine I, Leger J, Camand OJ, Sobrier ML, Dastot-Le Moal F, Duquesnoy P, Abitbol M, Czernichow P et al. 2001 Syndromic short stature in patients with a germline mutation in the LIM homeobox LHX4. American Journal of Human Genetics 69 961-968. (doi:10.1086/323764)

Miyagawa S, Matsumaru D, Murashima A, Omori A, Satoh Y, Haraguchi R, Motoyama J, Iguchi T, Nakagata N, Hui CC et al. 2011 The role of sonic hedgehog-Gli2 pathway in the masculinization of external genitalia. Endocrinology 152 2894-2903. (doi:10.1210/en.2011-0263)

Paulo SS, Fernandes-Rosa FL, Turatti W, Coeli-Lacchini FB, Martinelli CE, Nakiri GS, Moreira AC, Santos AC, de Castro M \& Antonini SR 2015 Sonic Hedgehog mutations are not a common cause of congenital hypopituitarism in the absence of complex midline cerebral defects. Clinical Endocrinology 82 562-569. (doi:10.1111/cen.12565)

Phillips JA III \& Cogan JD 1994 Genetic basis of endocrine disease. 6. Molecular basis of familial human growth hormone deficiency. Journal of Clinical Endocrinology and Metabolism 78 11-16.
Rahimov F, Ribeiro LA, de Miranda E, Richieri-Costa A \& Murray JC 2006 GLI2 mutations in four Brazilian patients: how wide is the phenotypic spectrum? American Journal of Medical Genetics. Part A 140 2571-2576. (doi:10.1002/ajmg.a.31370)

Roessler E, Du YZ, Mullor JL, Casas E, Allen WP, Gillessen-Kaesbach G, Roeder ER, Ming JE, Ruiz i Altaba A \& Muenke M 2003 Loss-of-function mutations in the human GLI2 gene are associated with pituitary anomalies and holoprosencephaly-like features. PNAS $\mathbf{1 0 0}$ 13424-13429. (doi:10.1073/pnas.2235734100)

Roessler E, Ermilov AN, Grange DK, Wang A, Grachtchouk M, Dlugosz AA \& Muenke M 2005 A previously unidentified amino-terminal domain regulates transcriptional activity of wild-type and disease-associated human GLI2. Human Molecular Genetics 14 2181-2188. (doi:10.1093/ $\mathrm{hmg} / \mathrm{ddi} 222$ )

Ruiz i Altaba A, Palma V \& Dahmane N 2002 Hedgehog-Gli signalling and the growth of the brain. Nature Reviews. Neuroscience 3 24-33. (doi:10.1038/ nrn704)

Sasaki H, Nishizaki Y, Hui C, Nakafuku M \& Kondoh H 1999 Regulation of Gli2 and Gli3 activities by an amino-terminal repression domain: implication of Gli2 and Gli3 as primary mediators of Shh signaling. Development 126 3915-3924.

Solomon NM, Ross SA, Forrest SM, Thomas PQ, Morgan T, Belsky JL, Hol FA, Karnes PS, Hopwood NJ, Myers SE et al. 2007 Array comparative genomic hybridisation analysis of boys with X-linked hypopituitarism identifies a 3.9 Mb duplicated critical region at Xq27 containing SOX3. Journal of Medical Genetics 44 e75. (doi:10.1136/jmg.2007.049049)

Solomon BD, Lacbawan F, Mercier S, Clegg NJ, Delgado MR, Rosenbaum K, Dubourg C, David V, Olney AH, Wehner LE et al. 2009 Mutations in ZIC2 in human holoprosencephaly: description of a novel ZIC2-specific phenotype and comprehensive analysis of 157 individuals. Journal of Medical Genetics 47 513-524. (doi:10.1136/jmg.2009.073049)

Solomon BD, Pineda-Alvarez DE, Gropman AL, Willis MJ, Hadley DW \& Muenke M 2012 High intellectual function in individuals with mutation-positive microform holoprosencephaly. Molecular Syndromology 3 140-142. (doi:10.1159/000341253)

Treier M, O'Connell S, Gleiberman A, Price J, Szeto DP, Burgess R, Chuang PT, McMahon AP \& Rosenfeld MG 2001 Hedgehog signaling is required for pituitary gland development. Development 128 377-386.

Triulzi F, Scotti G, di Natale B, Pellini C, Lukezic M, Scognamiglio M \& Chiumello G 1994 Evidence of a congenital midline brain anomaly in pituitary dwarfs: a magnetic resonance imaging study in 101 patients. Pediatrics 93 409-416.

Vaaralahti K, Raivio T, Koivu R, Valanne L, Laitinen EM \& Tommiska J 2012 Genetic overlap between holoprosencephaly and Kallmann syndrome. Molecular Syndromology 3 1-5. (doi:10.1159/000338706)

Villavicencio EH, Walterhouse DO \& Iannaccone PM 2000 The sonic hedgehog-patched-gli pathway in human development and disease. American Journal of Human Genetics 67 1047-1054. (doi:10.1016/ S0002-9297(07)62934-6)

Wang Y, Martin JF \& Bai CB 2010 Direct and indirect requirements of Shh/Gli signaling in early pituitary development. Developmental Biology 348 199-209. (doi:10.1016/j.ydbio.2010.09.024)

Woods KS, Cundall M, Turton J, Rizotti K, Mehta A, Palmer R, Wong J, Chong WK, Al-Zyoud M, El-Ali M et al. 2005 Over- and underdosage of SOX3 is associated with infundibular hypoplasia and hypopituitarism. American Journal of Human Genetics 76 833-849. (doi:10.1086/430134)

Wu W, Cogan JD, Pfaffle RW, Dasen JS, Frisch H, O'Connell SM, Flynn SE, Brown MR, Mullis PE, Parks JS et al. 1998 Mutations in PROP1 cause familial combined pituitary hormone deficiency. Nature Genetics 18 147-149. (doi:10.1038/ng0298-147)

Zhu X, Gleiberman AS \& Rosenfeld MG 2007 Molecular physiology of pituitary development: signaling and transcriptional networks. Physiological Reviews 87 933-963. (doi:10.1152/physrev.00006.2006)

Received in final form 16 March 2015 Accepted 1 April 2015

Published by Bioscientifica Ltd. http://jme.endocrinology-journals.org

DOI: 10.1530/JME-15-0009
(C) 2015 Society for Endocrinology Printed in Great Britain 